\title{
COMPARISON LOW-DENSITY LIPOPROTEIN CHOLESTEROL LEVELS CALCUTATION USING THE NOVEL METHOD BY MARTIN VS THE FRIEDEWALD EQUATION, IN TYPE 2 DIABETIC PATIENTS
}

J Sequeira Duarte ${ }^{1}$, Jorge Azinheira ${ }^{2}$

1 - Endocrinology, 2- Clinical Pathology Departments at Centro Hospitalar de Lisboa Ocidental

\section{Background}

Low-density lipoprotein cholesterol (LDL-C) is usualy estimated using the Friedewald equation. This equation assumes a fixed factor of 5 for the ratio of triglycerides to very low-density lipoprotein cholesterol (TG:VLDL-C); however, the actual TG:VLDLC ratio varies significantly across the range of triglyceride and cholesterol levels. A new method was proposed by Martin,S and co-workers using NHANES data.

\section{Objectives}

We aimed to evaluate the concordance Friedewald formula with the new method for LDL-C estimation from the standard lipid profile using an adjustable factor for the TG:VLDL-C ratio.

\section{Methods}

We used the results of 40339 consecutive clinical lipid profiles obtained from 2000 through 2015 from patients of our outpatient clinic, at our hospital lab. The measurements were done mainly in type 2 diabetic - 66,1\%. Females were 52\% of cases Cholesterol concentrations were directly measured after vertical spin density. LDL-C was measured if triglycerides over $400 \mathrm{mg} / \mathrm{dL}$ and calculated by Friedewald formula if lower. Data was analysed in SPSS package v20.

\section{TG:VLDL-C ratio tables by Martin et al}

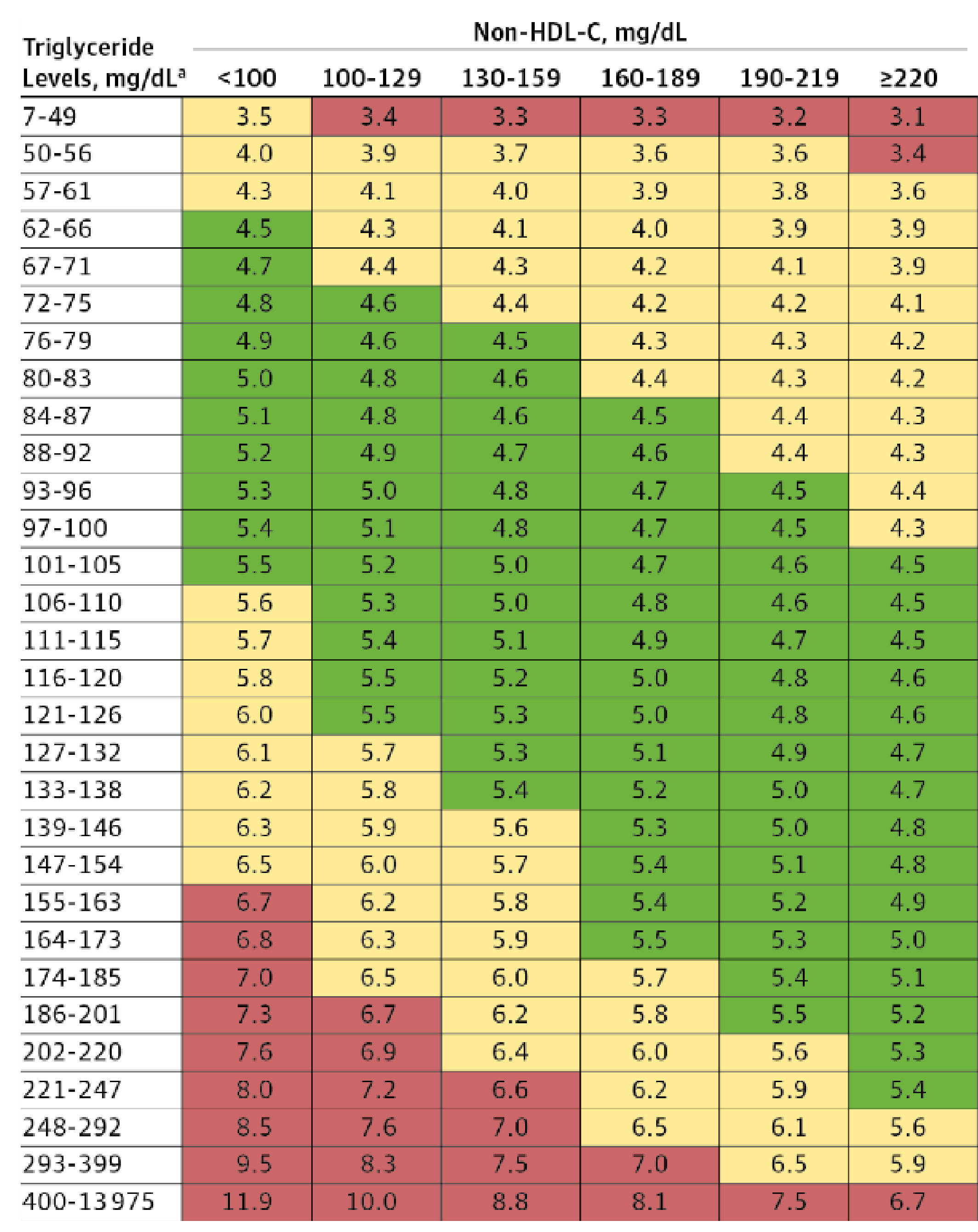

Median for the Ratio of Triglycerides to VLDL-c by Non-HDL-c and Triglyceride Strata (180Cell)

Green, 4.5-5.5; yellow, 3.5-4.4, 5.6-6.5; red, $<3.5,>6.5$.

Friedewald formula will tend to underestimate LDL

JAMA.

2013;310(19):2061-

2068.
Patient Characteristics
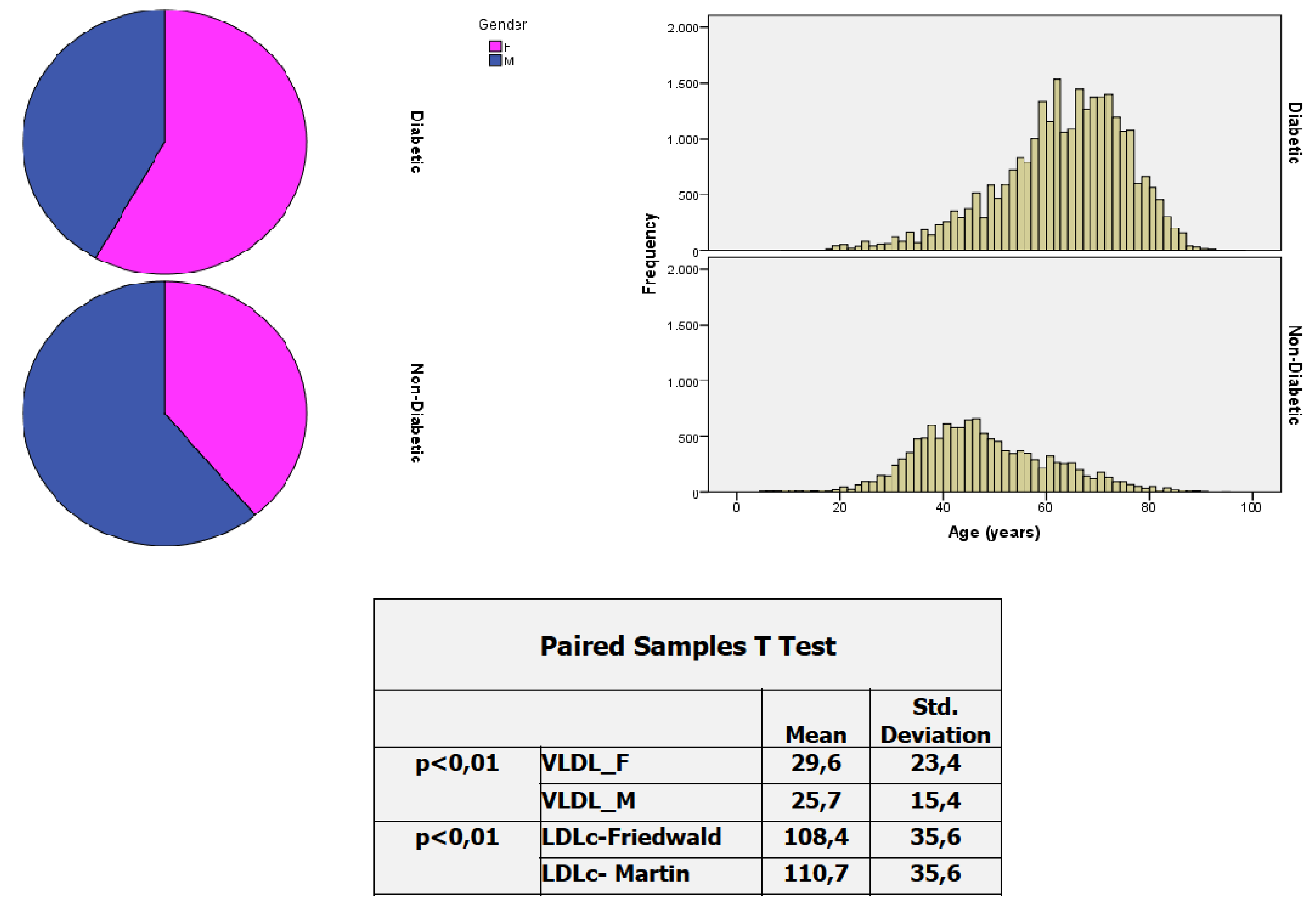

LDLc- Martin

LDLc-Friedwald
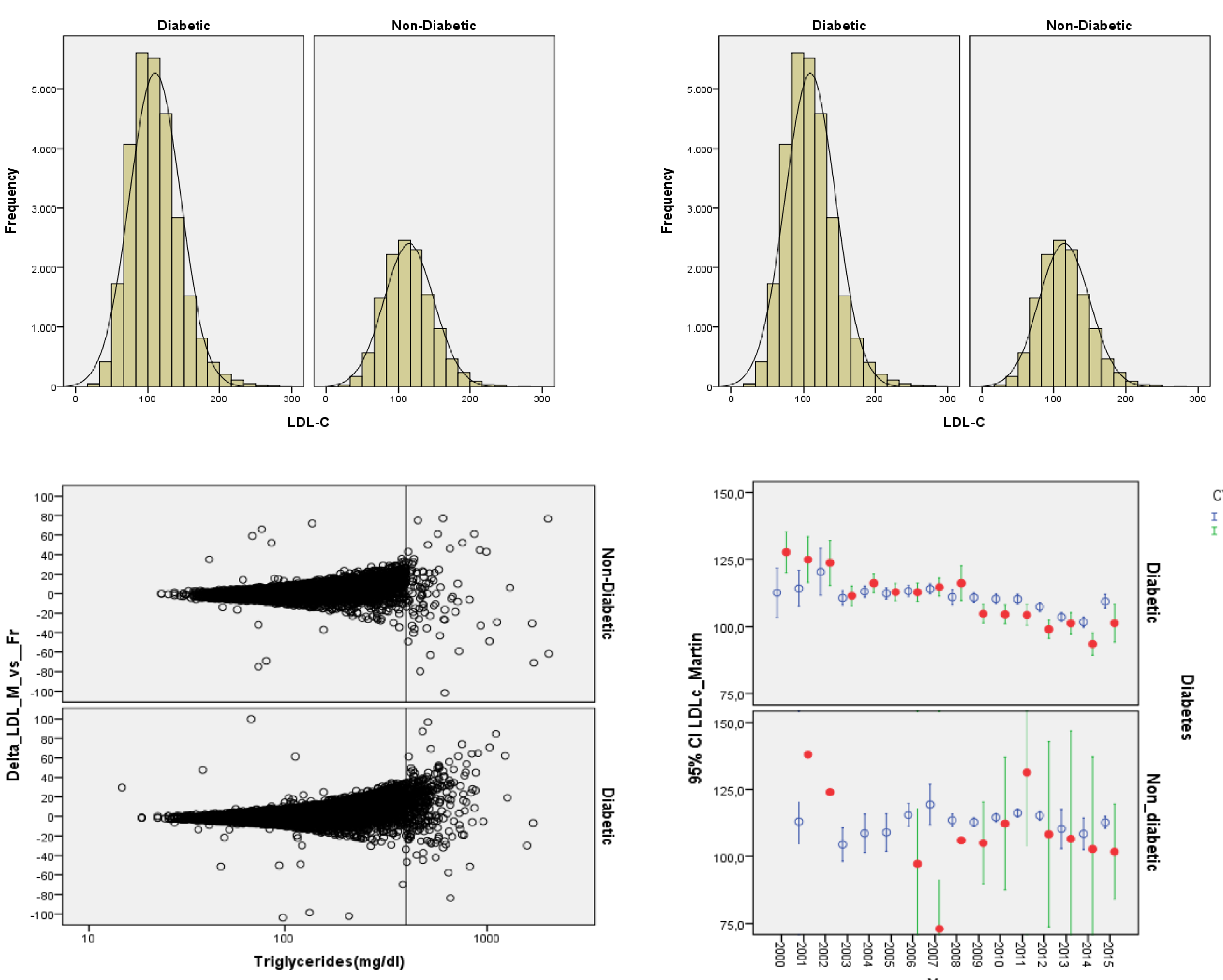

\section{Results}

Diabetic patients had lower LCL-C levels than non diabetics (92 vs $101 \mathrm{mg} / \mathrm{dl}-$ $p<0,001)$. Results of LCL-C are highly correlated in the all lipid profiles $(93 \% p<0,001)$ but mean values are 108,3 vs $96,4 \mathrm{mg} / \mathrm{dL}$ using Friedewald formula vs the new method. Wilcokson rank test find significant differences between the 2 methods $(p<0,001)$.

\section{Conclusions}

This novel method to estimate LDL-C using an adjustable factor for the TG:VLDL-C ratio produces significant lower values of LDL-C than the Friedewald equation. These findings require external validation, as well as assessment of their clinical importance. The implementation of the new method into clinical practice is particular relevant when triglycerides are higher than $400 \mathrm{mg} / \mathrm{dl}$.

\section{Bibliography}

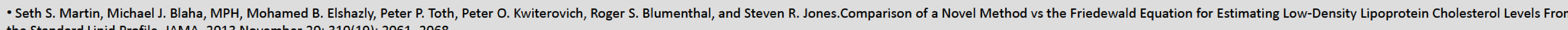

- Friedewald WT, Levy RI, Fredrickson DS. Estimation of the concentration of low-density lipoprotein cholesterol in plasma, without use of the preparative ultracentrifuge. Clin Chem. 1972; 18(6):499-502.

- DeLong DM, DeLong ER, Wood PD, Lippel K, Rifkind BM. A comparison of methods for the estimation of plasma low- and very low-density lipoprotein cholesterol: the Lipid Research Clinics Prevalence Study. JAMA. 1986; 256(17):2372-2377.

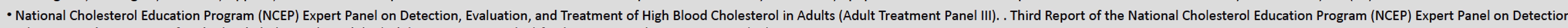
Evaluation, and Treatment of High Blood Cholesterol in Adults (Adult Treatment Panel III) final report. Circulation. 2002; 106(25):3143-3421.

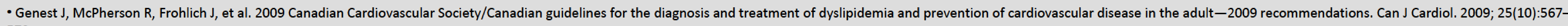

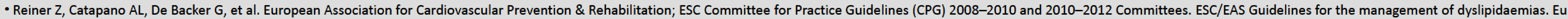
Heart J. 2011; 32(14):1769-1818. 